\title{
Research Paper: TheEffects of Acceptanceand Commitment Therapy on the Sense of Coherence, Locus of Control, and Posttraumatic Growth in Patients With Multiple Sclerosis
}

\author{
Jalal Younesi $^{1}$ (D), Javad Kazemi ${ }^{* *}$ (D), Mohammad Saeed Khanjani ${ }^{1}$ (D), Asghar Dadkhah ${ }^{1}$ (D), Akbar Biglarian² (D), Banafsheh Ebrahimi Barmi ${ }^{3}$ (D) \\ 1. Department of Counseling, Faculty of Counseling, University of Social Welfare and Rehabilitation Sciences, Tehran, Iran \\ 2. Department of Statistics, Faculty of Statistics, University of Social Welfare and Rehabilitation Sciences, Tehran, Iran. \\ 3. Department of Rehabilitation Management, Faculty of Rehabilitation Management, University of Social Welfare and Rehabilitation Sciences, Tehran, Iran
}

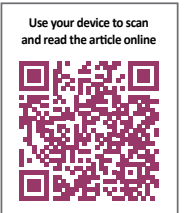

chtation: Younesi J, Kazemi J, Khanjani MS, Dadkhah A, Biglarian A, Ebrahimi Barmi B. The Effects of Acceptance and Commitment Therapy on the Sense of Coherence, Locus of Control, and Posttraumatic Growth in Patients With Multiple Sclerosis. Iranian Rehabilitation Journal. 2020; 18(4):445-454. http://dx.doi.org/10.32598/irj.18.4.1016.2

\section{(i) (3)}

Article info:

Received: 06 Dec 2019

Accepted: 04 Nov 2020

Available Online: 01 Dec 2020

Keywords:

Acceptance and Commitment Therapy (ACT), Multiple sclerosis, Sense of Coherence (SOC), Locus of control, Posttraumatic Growth (PTG)

\section{ABSTRACT}

Objectives: This study aimed to determine the effects of Acceptance and Commitment Therapy (ACT) on the Sense of Coherence (SOC), Locus of Control (LoC), and Posttraumatic Growth (PTG) in patients with Multiple Sclerosis (MS). These factors were explored according to the prevalence of psychological problems in these patients.

Methods: This was a quasi-experimental study with a pre-test, post-test and a control group design. The study population included all patients with MS from Iran's MS Association in Tehran City, Iran. The study sample included 30 patients ( $n=15 /$ group) who were selected by purposive sampling technique and according to the study inclusion and exclusion criteria. The study participants were randomly assigned to the experimental and control groups. After obtaining necessary permissions and informed consent, a pre-test was initially performed. The instruments used in this study were the 29-item Antonovsky's Sense of Coherence Scale; the 29-item Julian Rotter's Locus of Control Scale, and the 21-item Tedeschi and Calhoun's Posttraumatic Growth scale. Several studies supported the reliability and validity of these scales. The experimental group received 8 sessions (once a week, each session: $1.5 \mathrm{~h}$ ) of group Acceptance and Commitment Therapy (ACT). However, the control group received no intervention. After the intervention, according to the instructions, the post-test was performed. Data analysis was conducted using SPSS V. 21. Multivariate Analysis of Covariance (MANCOVA) was performed to examine between-group differences data.

Results: The study findings indicated that ACT was effective on the SOC; however, it had no significant effect on the LoC and PTG $(\mathrm{P}=0.05)$.

Discussion: Participation in ACT sessions could enhance the SOC of patients with MS. Accordingly, it can be improved by accepting and enhancing these patients' commitment to change through psychotherapy approach and increasing their SOC.

\section{"Corresponding Author:}




\section{Highlights}

- ACT can enhance the SOC of patients with MS.

- SOC contributes to the independence of patients with MS.

- SOC contributes to the enhanced psychological wellbeing of patients with MS.

\section{Plain Language Summary}

Patients with MS may be unable to prevent uncomfortable thoughts and emotions; however, they can modify their reaction to these thoughts and emotions through ACT. As a result, these thoughts and emotions become less annoying and harmful. Finally, patients with MS experience better emotions, which in turn, reinforces the SOC in them. The SOC provides the basis for personal independence, as the ultimate goal of rehabilitation.

\section{Introduction}

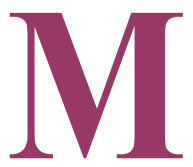

ultiple Sclerosis (MS) persists for a long time and affects one's healthy functioning [1]. The prevalence of MS is 33 per one million individuals [2]. Researchers have identified various factors, including genetics, autoimmune mechanisms, and in particular viral infections in this respect [3]. No definitive cure is discovered for MS. However, the rehabilitation teams are working to improve these patients' lives. In addition to physical rehabilitation, it is necessary to pay attention to psychological rehabilitation in patients with MS [4].

An aspect requiring psychological rehabilitation in patients with MS is difficulty in the Sense of Coherence (SOC). An SOC is defined as a general orientation, a deepening, enduring, and dynamic sense of confidence in life events; they are understandable, structured, and explainable; there exist resources to cope with them, and all these events are meaningful and deserve consideration [5]. By disrupting the psychological SOC, patients somehow lose their dominance over daily living activities. Accordingly, they feel influenced by external (rather than internal) characteristics, a concept recognized as the Locus of Control (LoC) [6].

If individuals with chronic illness achieve an SOC, which has an internal LoC, they will foster a sort of meaning beyond the illness; a meaning that will stimulate growth after being affected by the disease, i.e. called Posttraumatic Growth (PTG). This factor leads to growth in psychological components. PTG is a component of positive alternations, characterized by the experience of traumatic and unpleasant events with a return to a higher level of pre-traumatic function [7].
An approach that appears to contribute to the rehabilitation of patients with MS is Acceptance and Commitment Therapy (ACT). In other words, the treatment process is based on acceptance, commitment, and preventing avoidance behaviors. This principle seeks to teach patients to abandon the idea of suppressing anxiety; dissociate themselves from disturbing thoughts; and possibly allows the patients [8] to experience unpleasant emotions rather than avoiding them. Furthermore, some unpleasant emotions develop in patients with MS due to the unclear prognosis of the disease; avoidance behaviors in experiencing those emotions cause achieving decreased coherence [9]. By disrupting the SOC, one is drawn to the external LoC, and subsequently, the odds of PTG is reduced.

The purpose of ACT is to create flexibility. Moreover, flexible individuals experience a high SOC. Besides, in healthy individuals, a high SOC is associated with internal LoC. The more internal the LoC, the higher it is associated with PTG. However, for those with chronic illnesses, this matter remains unclear, especially in patients with MS whose prognosis is ambiguous. There exist a concurrent fear of aggravated illness and the hope of recovery. These thoughts may affect SOC, LoC, and PTG. This issue must be clarified for patients with MS. ACT addresses thought's context; however, other interventions focus on thought's content. Working on content is more difficult and time-consuming. This is especially true for individuals with chronic illnesses, like MS. However, ACT works faster, changes the context of thought as well as the reactions of patients to their thoughts and emotions.

Therefore, the current study aimed to determine the effects of ACT on the SOC, LoC, and PTG in patients 
with MS. These factors were explored according to the prevalence of psychological problems in these patients.

\section{Methods}

This was a quasi-experimental study with a pre-test, posttest and a control group design. The study population comprised patients with MS referring to Iran's MS Association in Tehran, City, Iran, from November 2018 to December 2018. Of 69 patients with MS, 30 were randomly selected by purposive sampling method. Accordingly, the study subjects were divided into the experimental and control groups ( $n=15 /$ group). The following tools were used to collect the necessary data:

1) Antonovsky's 29-item SOC scale [10]: It consists of the subscales of comprehensibility, manageability, and meaningfulness. The questionnaire's scoring is based on a Likert-type scale; each question has 7 items, ranging from one to 7. Generally, the minimum and maximum obtainable scores are 29 and 203, respectively. The scores 2958 indicate low coherence, 58-116 demonstrate moderate coherence, and the scores $>116$ reflect high coherence. A study explored the validity and reliability of the 29. item questionnaire concerning the data obtained from 20 countries, and the following results were obtained. In 26 studies using the 29-item questionnaire, Cronbach's alpha coefficient for internal consistency was equal to $0.82-0.95$. The correlation obtained from the test-retest method indicated a significant stability of 0.54 within two years. Ericsson and Lindstrom performed a systematic review on 458 articles and 13 doctoral dissertations; they concluded that the questionnaires of the Sense of Coherence (29-item \& 13-item versions) were valid and reliable. In Iran, Alipour et al. obtained a Cronbach's alpha coefficient of 0.96 for the same. Besides, the construct validity of this questionnaire was calculated as $76 \%$ [11].

2) Julian Rotter's 29-item LoC scale [12]: It consists of two options of A and B, scored as one and zero, respectively. Of the 29 questions, questions 1, 8, 14, 19, 24, and 28 are filler items and receive no score. Of the remaining 23 questions, a score of $>9$ presents an external LoC, and a score of $<9$ suggests an internal LoC. Cronbach's alpha coefficient for this scale was obtained as 0.87 . Moreover, the reliability coefficient of the split-half method was reported to be 0.84 [13]. Jafri et al. approved the validity of the tool as per experts' opinions and obtained a Cronbach's alpha coefficient of 0.87 for it [14].

3) The Tedeschi and Calhoun's 21-item PTG scale [15] is responded on a 5-point Likert-type scale, i.e. the score 'zero' indicates strongly disagree, and the score 4 reflects strongly agree. It comprises 5 subscales of relationship with others, new facilities, personal power, spiritual change, and the value of life. Its Cronbach's alpha coefficient was measured as 0.90 . Besides, the same value for each subscale ranged from 0.67 to 0.85 [13]. In Iran, Mahmoodi et al. obtained a Cronbach's alpha coefficient of 0.92 for it, and the construct validity of this questionnaire was computed as $68.98 \%$ [16].

The study inclusion criteria included the age of 20-55 years, educational level of at least high-school diploma, residing in Tehran, and the period past the disease onset to be $\geq 1-5$ years. Furthermore, patients with the following MS types were studied: Primary Progressive MS (PPMS); Secondary Progressive MS (SPMS), and 3-Progressive-Relapsing MS (PRMS). Among the study groups, the patients with Expanded Disability Status Scale (EDSS) scores of 4-5 were selected.

The exclusion criteria included having RRMS, substance or alcohol abuse, undergoing another psychological treatment concurrently, $>2$ absenteeism sessions, and presenting cognitive problems, according to the MiniMental State Exam (MMSE).

The treatment was conducted based on Twohig's ACT protocol [17]; according to which, 8 weekly sessions (1.5 hours) were held at the MS Community Rehabilitation Clinic in Tehran. The content of the treatment sessions is summarized in Table 1.

Accordingly, the first pre-test was performed. Then, the experimental group was treated with 8 weekly sessions of ACT, each lasting 1.5 hours. However, the control group received no treatment during this period. After the treatment sessions, the post-test was administered.

The PTG questionnaire was completed at the post-test (three months after the end of the sessions); according to the research nature and the experts' opinions, PTG does not form immediately and may occur after the treatment [15].

Finally, the obtained data were analyzed in SPSS. The Mean \pm SD indices in the descriptive part and Multivariate Analysis of Covariance (MANCOVA), in the inferential part, were used. The Chi-squared test was applied to investigate the differences between the demographic characteristics of the experimental and control groups. This research was registered under the Code IRCT20180710040411N1. 
Table 1. The protocol of the presented ACT sessions

\begin{tabular}{|c|c|}
\hline Session & Protocol \\
\hline 1 & $\begin{array}{l}\text { Introducing and communicating with group members; explaining the general rules of the sessions; distributing the } \\
\text { questionnaires. }\end{array}$ \\
\hline 2 & $\begin{array}{l}\text { Discussing and evaluating MS-related experiences as well as the metaphor of 'someone in the well'; creating creative } \\
\text { despair. }\end{array}$ \\
\hline 3 & $\begin{array}{l}\text { Explaining 'control' as a problem to control the destructive effects of MS, as well as the metaphor of 'a ball in the pool'; } \\
\text { concerning controlling behaviors; assigning home tasks. }\end{array}$ \\
\hline 4 & $\begin{array}{l}\text { Reviewing behavioral tasks and commitment; introducing the fault; applying cognitive fault techniques; discussing the } \\
\text { 'lemon slice' metaphor; performing the technique of separation between self and thoughts; assigning the home task } \\
\text { of identifying the extent of knowing oneself identical with the thoughts related to MS. }\end{array}$ \\
\hline 5 & $\begin{array}{l}\text { Reviewing behavioral tasks and commitment; blaming oneself as the origin of MS as a problem separate from self, } \\
\text { while considering oneself as an observer; practicing separation between oneself, MS, internal experiences, and be- } \\
\text { havior. }\end{array}$ \\
\hline 6 & $\begin{array}{l}\text { Applying mindfulness techniques; discussing conflicts between experience and mind; mind modeling; training inner } \\
\text { experiences as a process; practicing mindfulness techniques by eating raisins. }\end{array}$ \\
\hline 7 & Introducing the concept of value; discovering the practical values of life before, during, and after MS development. \\
\hline 8 & $\begin{array}{l}\text { Understanding the nature of desire and commitment; determining patterns of practice corresponding with the in- } \\
\text { trinsic values discovered with MS disease and the action based on them; post-test summation and implementation. }\end{array}$ \\
\hline
\end{tabular}

Iranian Rehabilitation Journal

\section{Results}

The present study evaluated the effects of ACT on the SOC, LoC, and PTG in patients with MS $(n=15 /$ experimental \& control groups). Besides, MANCOVA assumptions are reported in Table 2 and Table 3.

Table 2 presents that the distribution of the studied variables in the sample was normal. This is because the Zvalues were not significant at $\mathrm{P}<0.05$.

Table 3 illustrates that the error variance of the variables in the study groups was homogeneous. This is because the $\mathrm{F}$-value was not significant at $\mathrm{P}<0.05$.

Table 4 highlights that the Chi-squared test value was not significant in any of the demographic variables. In other words, there was no significant difference in the demographic variables between the study groups.

According to Table 5, the mean changes of all 3 variables were negligible in the control group; however, in the experimental group, the mean change in the variable of SOC was significant and reached from 68.14 in the pre-test to 153.92 in the post-test. Furthermore, the LoC and PTG demonstrated no significant mean score changes. The MANCOVA was used to compare the experimental and control groups in terms of SOC, LoC, and PTG scores (Table 6).
By controlling the pre-test effect, ACT presented a significant and different effect on the study groups in the SOC. This is because the calculated F-value was significant at $\mathrm{P}<0.05$. However, in the variables of $\mathrm{LoC}$ and PTG, the effects of ACT were not significant (Table 6).

\section{Discussion}

The obtained results suggested that ACT increased the SOC in patients with MS; however, no significant changes were found in the LoC and PTG. In explaining these findings, it can be stated that individuals with strong SOC are more flexible in stressful events [18]. Therefore, the presented ACT possibly improved the flexibility of the study participants; accordingly, their SOC has increased.

ACT might have created an emotionally-accepting experience of emotion-regulation in the explored patients, i.e. changed the SOC in them. On the other hand, Antonovsky believed that unexpected and uncontrollable experiences and uncertain situations weaken the SOC [19].

It may be assumed that patients with MS include these experiences. Besides, the intervention group, regardless of the particular acquired skills, may have experienced reduced levels of emotion (uncontrollable \& unexpected). This might have been resulted from receiving ACT; consequently, the SOC has raised. Higher scores on the SOC have led to the adaptation to chronic diseases. 
Table 2. One-sample Kolmogorov-Smirnov test results

\begin{tabular}{cccc}
\hline & Variable & \multicolumn{2}{c}{ Index } \\
\cline { 3 - 4 } Group & SOC & $\mathbf{Z}$ & P \\
\hline \multirow{2}{*}{ Experimental } & LoC & 0.287 & 0.003 \\
& PTG & 0.247 & 0.003 \\
& SOC & 0.226 & 0.005 \\
\hline Control & LOC & 0.274 & 0.003 \\
& PTG & 0.254 & 0.011 \\
\hline
\end{tabular}

Iranian Rehabilitation Journal

Table 3. Levene's test results

\begin{tabular}{ccccc}
\hline Variable & F & df1 & df2 & P \\
\hline SOC & 0.22 & 1 & 27 & 0.64 \\
LoC & 2.11 & 1 & 27 & 0.15 \\
PTG & 0.62 & 1 & 27 & 0.43 \\
\hline
\end{tabular}

Iranian Rehabilitation \ournal

Table 4. Baseline measures concerning the demographic variables of the experimental and control groups

\begin{tabular}{cccccccc}
\hline - & Education & Age & Gender & $\begin{array}{c}\text { Marital } \\
\text { Status }\end{array}$ & Job & $\begin{array}{c}\text { The Extent of } \\
\text { Lesion }\end{array}$ & Duration \\
\hline $\mathrm{x}^{2}$ & 2 & 5.42 & 0 & 0.14 & 3.37 & 0 & 2.21 \\
$\mathrm{P}$ & 0.73 & 0.14 & 1 & 7.0 & 0.06 & 1 & 033 \\
\hline
\end{tabular}

Iranian Rehabilitation Journa

Moreover, some studies have supported it as a protective factor against the intolerable pain requirements for that disease [20, 21]. Some studies reported that the SOC, as a mediator variable, leads to adaptive strategies for coping with stress in patients with MS [5].

Mindfulness and ACT provide greater psychological adjustment for coping with trauma [21, 22]. Individuals with disabilities experience decreased cohesion due to the effects of physical limitations and the lack of control over their lives. Besides, in critical situations, their SOC is severely impaired, leading to further inappropriate behaviors and vulnerability [23]. The ultimate goal of ACT, in addition to flexibility, is a psychological adaptation to conditions (sometimes unchangeable), caused by illness. Therefore, this problem could explain the improved SOC in this study.
Additionally, there was a significant relationship between individual differences in the SOC and selecting a healthy lifestyle [24]. The effects of lifestyle interventions have been demonstrated on the SOC in individuals with mental health issues [25]; in other words, ACT is more of a lifestyle than a therapeutic approach. Therefore, ACT, using techniques, such as mindfulness and cognitive defusion, have modified the lifestyle of the investigated patients with MS. As a result, the relationship between lifestyle and cohesion has significantly changed in them.

According to other studies, a high SOC has accepted its limitations and, consequently, weakened the stigma associated with MS disease [26]. The present study focused on ACT in terms of accepting emotions due to the limitations associated with the disease; therefore, it seems to reduce the effects of MS stigma, leading to the increased SOC. 
Table 5. Descriptive indices in the SOC, LoC, and PTG before and after the intervention

\begin{tabular}{|c|c|c|c|c|}
\hline \multirow{3}{*}{ Variable } & \multicolumn{4}{|c|}{ Mean $\pm S D$} \\
\hline & \multicolumn{2}{|c|}{ Control Group } & \multicolumn{2}{|c|}{ Experimental Group } \\
\hline & \multicolumn{2}{|c|}{ Pre-test, Post-test } & \multicolumn{2}{|c|}{ Pre-test, Post-test } \\
\hline SOC & $66.72 \pm 83.24$ & $53.73 \pm 23.20$ & $14.68 \pm 89.21$ & $92.153 \pm 24.21$ \\
\hline LoC & $93.14 \pm 75.4$ & $80.13 \pm 78.3$ & $14 \pm 29.5$ & $57.15 \pm 79.4$ \\
\hline PTG & $53.23 \pm 83.6$ & $86.19 \pm 96.5$ & $28.23 \pm 27.9$ & $78.24 \pm 51.8$ \\
\hline
\end{tabular}

Iranian Rehabilitation Journal

Table 6. MANCOVA results to examine between-group differences in post-intervention research variables

\begin{tabular}{cccccccc}
\hline Variable & Source of Variance Index & Sum of Squares & df & MS & F & P & Eta Coefficient \\
\hline \multirow{2}{*}{ SOC } & Pre-test & 663.36 & 1 & 663.36 & 075.0 & 786.0 & 003.0 \\
& Group & 681.40509 & 1 & 641.40509 & 067.83 & 05.0 & 791.0 \\
& Error & 819.10728 & 22 & 674.487 & - & - & - \\
& Pre-test & 130.11 & 1 & 130.11 & 573.0 & 457.0 & 025.0 \\
LoC & Group & 273.43 & 1 & 273.43 & 22.2 & 150.0 & 092.0 \\
& Error & 030.427 & 22 & 410.19 & - & - & - \\
& Pre-test & 164.0 & 1 & 164.0 & 003.0 & 957.0 & 005.0 \\
PTG & Group & 80.129 & 1 & 80.129 & 33.2 & 141.0 & 096.0 \\
& Error & 85.1225 & 22 & 708.55 & - & - & - \\
\hline
\end{tabular}

No study has directly examined the effects of ACT on SOC. However, some research has employed other interventions, including Adlerian hope-therapy and lifestyle. The relevant results indicated a significant increase in the SOC among women with motor disabilities. Furthermore, mindfulness intervention was reported to positively influence SOC in patients with asthma [27]. Another study suggested that cognitive-behavioral happiness training intervention was effective on the SOC in patients with type 2 diabetes [28]. Therefore, the present study results were in line with those of the investigations mentioned above in terms of their effect on increasing the SOC.

The LoC is sometimes altered due to the removal of the external source factor [29]; there is an external agent in these patients and perhaps accepting this agent, rather than removing or altering the external factor, has failed to make a significant difference in the LoC scores. However, as a result of the treatment, not the method of the treatment and the therapeutic target, the LoC changes may also occur over time. There was also a relationship between the internal LoC and the problem-focused coping style [30].

ACT mainly focuses on the acceptance of emotions. A great body of literature revealed the effects of ACT on emotion regulation in different patients $[31,32]$. However, this intervention was unable to significantly change the LoC in the explored patients. Moreover, some studies have reported that $88 \%$ of patients with $\mathrm{S}$ have an $\mathrm{LoC}$, i.e. either modest or time-consuming, depending on the state of the disease. Such conditions probably change as soon as the disease achieves a stable mode. Increasing the source of external control is associated with the exacerbation of MS symptoms [33].

Contrary to the current study findings, demonstrating no significant difference in the mean LoC scores, another study indicated that ACT failed to decrease the sever- 
ity of the pain; however, it reduced the sense of paininduced disability in chronic diseases and created a sense of control in the patient [34].

The PTG occurs less frequently in resilient individuals. As a result of resilience following a traumatic event, one can usually return to the usual lifestyle without serious psychological damages. Resilience may create conditions where the individual is less likely to perceive a threat to self and the world. Thus, more-resilient individuals can further reduce the impact of the event. Considering that PTG requires creating meaning for a traumatic event, resilient individuals are less likely to engage in meaningful behaviors associated with growth. This is because they are unlikely to cope with the consequences of trauma; thus, as a result of resilience, there may be a limited opportunity or need for PTG [35].

According to some studies, ACT has increased resiliency in individuals [36]. In this study, unlike, it did not change with increased resilience in patients with MS after trauma. Inconsistent with the present study results, Amanollahi has reported the effectiveness of ACT on the PTG relating to the girls with emotional failure experience [37]. The present study overlooked investigating all 4 MS patient groups of benign (relapsing-remitting), and the other three groups including PPMS, SPMS, and PRMS. Among these groups, the patients with the EDSS index of 4-5 were selected. Besides, the lack of a control group for psychotherapy was a limitation of the present study. It was a quasi-experimental study, and no nuisance variables could be controlled. Finally, this study disregarded a follow-up assessment stage.

\section{Conclusion}

The main purpose of rehabilitation is to implement various rehabilitation sciences to identify, enhance, and apply the patient's remaining abilities in autonomy. The feeling of low cohesion reduces the patient's focus on these goals and leads to dependence and inactivity. Therefore, therapists can assist the patients to feel better regarding the chronicity of MS. ACT seems to be appropriate for achieving these goals, and it has been effective in increasing the SOC in patients with MS.

\section{Ethical Considerations}

\section{Compliance with ethical guidelines}

To comply with ethical considerations, an informed consent form was obtained from all study patients before conducting the study. Besides, we observed the principle of confidentiality and information secrecy. This study was approved by the Research Ethics Committee of the University of Social Welfare and Rehabilitation Sciences (Code: IR.USWR. REC.1397.019).

\section{Funding}

This research did not receive any grant from funding agencies in the public, commercial, or non-profit sectors.

\section{Authors' contributions}

Conceptualization: Jalal Younesi; Methodology: Asghar Dadkhah; Data collection: Banafsheh Ebrahimi Barmi; Data analysis: Akbar Biglarian, and Supervision: Mohammad Saeed Khanjani.

\section{Conflict of interest}

The authors declared no conflicts of interest.

\section{Acknowledgments}

We are extremely grateful to the staff of the University of Social Welfare and Rehabilitation Sciences. We also thank Iran's MS Association officials and all patients with MS for participating in this study.

\section{References}

[1] Tan-Kristanto S, Kiropoulos LA. Resilience, self-efficacy, coping styles and depressive and anxiety symptoms in those newly diagnosed with multiple sclerosis. Psychology, Health \& Medicine. 2015; 20(6):635-45. [DOI:10.1080/13548506.2014.9 99810] [PMID]

[2] Heydarpour P, Khoshkish S, Abtahi S, Moradi-Lakeh M, Sahraian MA. Multiple sclerosis epidemiology in Middle East and North Africa: A systematic review and meta-analysis. Neuroepidemiology. 2015; 44(4):232-44. [DOI:10.1159/000431042] [PMID]

[3] Mahad DH, Trapp BD, Lassmann H. Pathological mechanisms in progressive multiple sclerosis. The Lancet Neurology. 2015; 14(2):183-93. [DOI:10.1016/S1474-4422(14)70256-X]

[4] Haupts M, Seidel D. Rehabilitation in progressive multiple sclerosis. Swiss Archives of Neurology, Psychiatry and Psychotherapy. 2018; 169(06):183-4. [DOI:10.4414/sanp.2018.00592] 
[5] Calandri E, Graziano F, Borghi M, Bonino S. Coping strategies and adjustment to multiple sclerosis among recently diagnosed patients: The mediating role of sense of coherence. Clinical Rehabilitation. 2017; 31(10):1386-95. [DOI:10.1177/0269215517695374] [PMID]

[6] Bragazzi NL. The gap in the current research on the link between health locus of control and multiple sclerosis: Lessons and insights from a systematic review. Multiple Sclerosis International. 2013; 2013:972471. [DOI:10.1155/2013/972471] [PMID] [PMCID]

[7] Aflakseir A, Manafi F. Posttraumatic growth and its relationship with cognitive emotion regulation strategies in patients with multiple sclerosis in Shiraz, Iran. Practice in Clinical Psychology. 2018; 6(1):57-62. [DOI:10.29252/nirp. jpcp.6.1.57]

[8] Asqari S, Donyavi R. The effect of acceptance and commitment therapy on the life expectancy in patients with multiple sclerosis. Journal of Nursing and Midwifery Sciences. 2017; 4(3):69-74. [DOI:10.4103/JNMS.JNMS_8_17]

[9] Mirhashemi M, Najafi F. [Efficacy of solution-centered therapy on resiliency and sense of coherence among patients with multiple sclerosis (Persian)]. Medical Science Journal of Islamic Azad Univesity-Tehran Medical Branch. 2014 24(3):175-81. http:// tmuj.iautmu.ac.ir/article-1-838-en.html

[10] Eriksson M, Lindström B. Antonovsky's sense of coherence scale and the relation with health: A systematic review. Journal of Epidemiology \& Community Health. 2006; 60(5):37681. [DOI:10.1136/jech.2005.041616] [PMID] [PMCID]

[11] Alipour A, Sharif N. [Validity and reliability of sense of coherence $(\mathrm{SOC})$ questionnaire in university students (Persian)]. Pajoohande. 2010; 17(1):50-6. http://pajoohande. sbmu.ac.ir/article-1-1276-en.html

[12] Rotter J. Rotter internal-external locus of control scale. In: Halpert R, Hill R, editors. 28 Measures of Locus of Control. 2011. https://www.mccc.edu/ jenningh/Courses/documents/Rotter-locusofcontrolhandout.pdf

[13] Spaapen DL, Waters F, Brummer L, Stopa L, Bucks RS. The Emotion Regulation Questionnaire: Validation of the ERQ-9 in two community samples. Psychological Assessment. 2014; 26(1):46-54. [DOI:10.1037/a0034474] [PMID]

[14] Jomehri F, Najafi M, Jafari E, Sohrabi F. [The Relation ship between type $C$ personality, locus of control and hardiness in patients suffering from cancer and normal subjects (Persian)]. Journal of Clinical Psychology. 2009; 1(1):47-66. [DOI: 10.22075/JCP.2017.1997]

[15] Tedeschi RG, Addington E, Cann A, Calhoun LG. Posttraumatic growth: Some needed corrections and reminders. European Journal of Personality. 2014; 28(4):350-1.

[16] Mahmoudi SJS, Rahimi CH, Mohammadi N. [Psychometric properties of post traumatic growth questionnaire (Persian)]. Psychological Methods and Models. 2013; 3(12):93-108. https://www.sid.ir/en/journal/ViewPaper. aspx?id=386761

[17] Bluett EJ, Homan KJ, Morrison KL, Levin ME, Twohig MP. Acceptance and commitment therapy for anxiety and OCD spectrum disorders: An empirical review. Journal of Anxiety Disorders. 2014; 28(6):612-24. [DOI:10.1016/j. janxdis.2014.06.008] [PMID]
[18] Weissbecker I, Salmon P, Studts JL, Floyd AR, Dedert EA Sephton SE. Mindfulness-based stress reduction and sense of coherence among women with fibromyalgia. Journal of Clinical Psychology in Medical Settings. 2002; 9(4):297-307. [DOI:10.1023/A:1020786917988]

[19] Schnyder U, Büchi S, Mörgeli H, Sensky T, Klaghofer R. Sense of coherence-a mediator between disability and handicap? Psychotherapy and Psychosomatics. 1999; 68(2):102-10. [DOI:10.1159/000012320] [PMID]

[20] Valdivia-Salas S, Sheppard SC, Forsyth JP. Acceptance and commitment therapy in an emotion regulation context. In: Kring AM, Sloan DM, editors. Emotion regulation and psychopathology: A transdiagnostic approach to etiology and treatment. New York: The Guilford Press; 2010. https:/ / psycnet.apa.org/record/2009-21674-000

[21] Lashani L, Farhoudian A, Azkhosh M, Dolatshahee B, Saadati H. Acceptance and Commitment Therapy in the Satisfaction of Veterans with Spinal Cord Injuries Spouses. Iranian Rehabilitation Journal. 2013; 11(3):56-60. http://irj.uswr. ac.ir/article-1-321-en.html

[22] Thompson RW, Arnkoff DB, Glass CR. Conceptualizing mindfulness and acceptance as components of psychological resilience to trauma. Trauma, Violence, \& Abuse. 2011; 12(4):220-35. [DOI:10.1177/1524838011416375] [PMID]

[23] Müller J, Hess J, Hager A. Sense of coherence, rather than exercise capacity, is the stronger predictor to obtain healthrelated quality of life in adults with congenital heart disease. EuropeanJournal of Preventive Cardiology. 2014; 21(8):949-55. [DOI:10.1177/2047487313481753] [PMID]

[24] Wainwright NWJ, Surtees PG, Welch AA, Luben RN, Khaw K-T, Bingham SA. Healthy lifestyle choices: Could sense of coherence aid health promotion? Journal of Epidemiology \& Community Health. 2007; 61(10):871-6. [DOI:10.1136/ jech.2006.056275] [PMID] [PMCID]

[25] Forsberg KA, Björkman T, Sandman PO, Sandlund M. Influence of a lifestyle intervention among persons with a psychiatric disability: A cluster randomised controlled trail on symptoms, quality of life and sense of coherence. Journal of Clinical Nursing. 2010; 19(11-12):1519-28. [DOI:10.1111/ j.1365-2702.2009.03010.x] [PMID]

[26] Broersma F, Oeseburg B, Dijkstra J, Wynia K. The impact of self-perceived limitations, stigma and sense of coherence on quality of life in multiple sclerosis patients: Results of a crosssectional study. Clinical Rehabilitation. 2018; 32(4):536-45. [DOI:10.1177/0269215517730670] [PMID] [PMCID]

[27] Darskhan M, Vaziri S. [The effectiveness of mindfulnessbased stress reduction on the sense of psychological integrity and coping style in patients with asthma (Persian)]. Thought \& Behavior in Clinical Psychology. 2017; 11(42):47-56. https://jtbcp.riau.ac.ir/article_1036_169d69199632a948ba9e6ca de420e8f9.pdf

[28] Hosseini M, Abdekhodaie MS. [Effects of cognitive-behavioral fordyce happiness training on sense of coherence in patients with type 2 diabetes (Persian)]. Journal of Neyshabur University of Medical Sciences. 2017; 4(4):1-10. http://journal.nums.ac.ir/article-1-306-fa.html

[29] Jain M, Singh S. Locus of control and its relationship with mental health and adjustment among adolescent females. Journal of Mental Health and Human Behaviour. 2015; 20(1):16-21. [DOI:10.4103/0971-8990.164803] 
[30] Bayrami M, Hashemi T, Alizadeh Gooradel J, BadenjaniSM. [Prediction of Vulnerability against stress on the social support, coping strategies and locus of control (Persian)]. Quarterly Social Psychology Research. 2012; 2(5):55-68. http:// www.socialpsychology.ir/article_123145.html?lang=en

[31] Khakbaz H, Farhoudian A, Azkhosh M, Dolatshahi B, Karami H, Massah O. The Effectiveness of group acceptance and commitment therapy on emotion regulation in methamphetamine-dependent individuals undergoing rehabilitation. International Journal of High Risk Behaviors \& Addiction. 2016; 5(4):e28329. [DOI:10.5812/ijhrba.28329]

[32] Ghouchani S, Molavi N, Massah O, Sadeghi M, Mousavi $\mathrm{SH}$, Noroozi M, et al. Effectiveness of acceptance and commitment therapy (ACT) on aggression of patients with psychosis due to methamphetamine use: A pilot study. Journal of Substance Use. 2018; 23(4):402-7. [DOI:10.1080/14659891.2 018.1436602]

[33] Vuger-Kovačić D, Gregurek R, Kovačić D, Vuger T, Kalenić B. Relation between anxiety, depression and locus of control of patients with multiple sclerosis. Multiple Sclerosis Journal. 2007; 13(8):1065-7. [DOI:10.1177/1352458507077629] [PMID]

[34] Wicksell RK, Olsson GL, Hayes SC. Psychological flexibility as a mediator of improvement in acceptance and commitment therapy for patients with chronic pain following whiplash. European Journal of Pain. 2010; 14(10):1059.e1-11. [DOI:10.1016/j.ejpain.2010.05.001] [PMID]

[35] Levine SZ, Laufer A, Stein E, Hamama-Raz Y, Solomon Z Examining the relationship between resilience and posttraumatic growth. Journal of Traumatic Stress. 2009; 22(4):282-6. [DOI:10.1002/jts.20409] [PMID]

[36] Farahani M, Heydari H. [The effectiveness of acceptance and commitment therapy on resiliency of MS patients (Persian)]. Journal of Rooyesh-e-Ravanshenasi. 2018; 7(6):149-62. http://frooyesh.ir/article-1-580-fa.html

[37] Amanollahi A, Zare M, Rajabi Gh. [The Effectiveness of acceptance and commitment therapy on the post-traumatic growth in girls with emotional breakdown (Persian)]. Journal of Counseling Research. 2018; 16(64):4-29. http://irancounseling.ir/journal/article-1-593-en.html 
This Page Intentionally Left Blank 